Journal of Linguistics

http://journals.cambridge.org/LIN

Additional services for Journal of Linguistics:

Email alerts: Click here

Subscriptions: Click here

Commercial reprints: Click here

Terms of use : Click here

\title{
Negation, 'presupposition' and the semantics/pragmatics distinction
}

\section{ROBYN CARSTON}

Journal of Linguistics / Volume 34 / Issue 02 / September 1998, pp 309 - 350

DOI: null, Published online: 08 September 2000

Link to this article: http://journals.cambridge.org/abstract_S0022226798007063

How to cite this article:

ROBYN CARSTON (1998). Negation, 'presupposition' and the semantics/pragmatics distinction. Journal of Linguistics, 34, pp 309-350

Request Permissions : $\underline{\text { Click here }}$ 
J. Linguistics 34 (1998), 309-350. Printed in the United Kingdom

(C) 1998 Cambridge University Press

\title{
Negation, 'presupposition' and the semantics/pragmatics distinction ${ }^{1}$
}

\author{
ROBYN CARSTON
}

\author{
Department of Phonetics and Linguistics, University College London
}

(Received 23 February I996; revised 7 April I998)

\begin{abstract}
A cognitive pragmatic approach is taken to some long-standing problem cases of negation, the so-called presupposition denial cases. It is argued that a full account of the processes and levels of representation involved in their interpretation typically requires the sequential pragmatic derivation of two different propositions expressed. The first is one in which the presupposition is preserved and, following the rejection of this, the second involves the echoic (metalinguistic) use of material falling in the scope of the negation. The semantic base for these processes is the standard antipresuppositionalist wide-scope negation. A different view, developed by BurtonRoberts (I989a, b), takes presupposition to be a semantic relation encoded in natural language and so argues for a negation operator that does not cancel presuppositions. This view is shown to be flawed, in that it makes the false prediction that presupposition denial cases are semantic contradictions and it is based on too narrow a view of the role of pragmatic inferencing.
\end{abstract}

\section{INTRODUCTION}

I am going to look at some recent accounts of the interpretation of certain negative sentences, those exemplified in (I)-(3), concentrating on the only too familiar one in (I):

(I) The king of France isn't bald - there is no king of France.

(2) I don't regret inviting him - he jolly well gate-crashed.

(3) I haven't stopped smoking - I've never smoked in my life.

These are cases of what is known as 'presupposition'-cancelling negation ( $\mathrm{P}$ cancellation, from now on), which is usually felt to be rather marked or unnatural. This interpretation of negation would not generally be the one to come to mind if the first negative sentence in each case were presented in isolation. For instance, (I) without the second clause would usually be taken

[I] The impetus for this paper came from the work of Noel Burton-Roberts, as will be amply obvious throughout. Although I take a very different line from him, the development of my position has been greatly furthered by the interesting discussions I have had with him and his generous encouragement. I am grateful to the two $J L$ referees of the paper who made many useful suggestions, both substantive and stylistic. Many thanks also to Mira Ariel, Ad Foolen, Thorstein Fretheim, Larry Horn, Eun-Ju Noh, Neil Smith, Deirdre Wilson and Vladimir Zegarac who have each, in their different ways, helped me to plug on. 
to be predicating non-baldness of an existing king of France, and (2) without the second clause would be interpreted as my having invited him and not regretting having done so. However, the more marked interpretation is easily derived once the second clause, in which the presupposed proposition is explicitly denied, has been processed, and the interpretation seems to be perfectly acceptable. It is this interpretation that I want to focus on here since it has recently been the subject of an interesting and, so far, unresolved debate, which raises questions about (a) the nature of negation, (b) the proper treatment of those implications standardly called 'presuppositions' and (c) the wider issue of the respective roles of semantics and pragmatics in utterance interpretation.

Both Horn (1985, I989) and Burton-Roberts (I989a, b) (henceforth B-R) treat (I)-(3) as involving what they call metalinguistic negation, which they take to be a pragmatic phenomenon, quite distinct from standard truthfunctional descriptive negation. It has the approximate meaning 'I object to $\mathrm{U}$ ' or ' $\mathrm{U}$ is inappropriate/unassertable', where $\mathrm{U}$ is an utterance of the positive counterpart of the negative sentence. For the examples under discussion, the idea is that the positive form, say 'The king of France is bald', is being rejected as inappropriate because one of its presuppositions, here the existential one, is not fulfilled, as the follow-up clause makes explicit. The metalinguistic understanding of the negative sentence is derived by a hearer when the descriptive, truth-based, understanding, which is accessed first, is rejected for some reason.

B-R's primary commitment is to establishing the presuppositional nature of natural language and his interest in a metalinguistic analysis of (I)-(3) is geared to this end. On his view, presupposition is a semantic relation encoded into the language system. Horn, on the other hand, stands with the antipresuppositionalists, in that he believes that there is no such semantic relation additional to the semantic relation of entailment and that 'presuppositional' effects are to be understood pragmatically. B-R (I989a, b) claims that Horn's commitments lead him into a double bind, whereby he is explicitly supporting the view which disavows the existence of semantic presupposition and simultaneously, due to his treatment of these examples as metalinguistic negations, implicitly supporting the semantic presuppositionalists. Horn (I990) continues to protest his freedom from this error, maintaining his overt support for a presupposition-free semantics. In my attempt to find an adequate account of the interpretation of these examples and of the processes involved in arriving at that interpretation, I shall explore the alleged Hornian dilemma. I believe that one consequence of my account is a vindication of Horn's general stance with regard to these examples and the evaporation of any appearance of dilemma.

Before getting under way, I should point out that I am concerned here just with what Horn ( 1989 : chapter 7) calls the 'predicate denial' manifestation of negation; that is, the denial of the applicability of the predicate to the 


\section{SEMANTICS / PRAGMATICS DISTINCTION}

subject. This is one way of construing a negation whose scope is maximally wide; its domain is essentially the same as that of the Fregeans' sentence (or propositional) negation operator, but, arguably, it is a more natural way of viewing the manifestations of wide scope negation in natural languages. It is typically affixed to an auxiliary verb and pronounced [ənt], as in the examples in (I)-(3), though it may also occur as the free morpheme pronounced [not]. That is, we won't be considering here 'term (constituent) negation', which necessarily maintains existential/factive commitments, although it does make a brief appearance in section 5.2. For example, on its predicate term negation interpretation, 'The king of France is not happy' predicates the negative term 'not happy' of the king of France. Predicate denial (or sentence negation), on the other hand, may or may not be interpreted as maintaining existential entailments; for an anti-presuppositionalist such as Horn the possible grounds for a predicate denial include the nonexistence of anything which the subject denotes. For a semantic presuppositionalist, such as B-R, this would not be a possible ground, as the negation of a sentence (or its predicate denial) does not touch its presuppositions.

The next two sections are essentially scene-setting. Section 2 surveys the two rival positions on these sentences, which are my point of departure. Section 3 takes a look at the phenomenon of metalinguistic negation, which figures prominently in one of the two analyses outlined in section 2 and in a third analysis, which I shall propose in section 6. Section 4 spells out some of the differences between B-R and Horn, in particular B-R's allegation of inconsistent commitments on Horn's part. Section 5 has a demolitionary purpose: it presents (strong, I think) evidence against two assumptions that underpin B-R's position: (a) that presupposition-denials (such as (I)-(3)) are semantic contradictions, and (b) that presupposition-denials are inevitably interpreted metalinguistically. The paper ends with some general but quite fundamental ruminations on the nature of pragmatics and the semantics/pragmatics distinction.

\section{THE TWO BASIC POSITIONS}

The names most readily associated with discussions of the semantics of these negative presuppositional sentences are Russell and Strawson. As is very well known, Russell accommodated the negation in example (I), by taking the negative sentence to have two possible logical forms; that is, to be ambiguous. In one of these logical forms, his quantificational semantics for definite descriptions takes wide scope over the negation operator, thereby leaving the existential implication unnegated (P-preservation), and in the other, the description falls within the scope of negation (P-cancellation). It is the latter that occurs in example (I). He thereby avoided any postulation of a semantic relation of presupposition and maintained the bivalency of the logic of such sentences. Strawson, on the other hand, advocated a univocal 
P-preserving negation operator; this followed from his fundamental distinction between presupposition and assertion, presuppositions precisely being those implications which must be fulfilled if a sentence and its corresponding negation are to succeed in making any assertion/statement at all. A problem with his approach, which is often pointed out, is that he gave no account of examples such as (I)-(3). Later semantic presuppositionalists addressed this matter by postulating two logical operators with negative force, the one P-preserving and the other P-cancelling, thus requiring that the logic of natural language be trivalent or, at least, that it admit truth-value gaps. There is a mild irony to be enjoyed here: semantic presuppositionalists, ostensibly followers of Strawson, the advocate of a univocal negation operator, have generally found it necessary to postulate an ambiguity in the negation operator, while the anti-presuppositionalist followers of Russell, who required a scope ambiguity in the negation operator, have generally advocated a semantically and syntactically unambiguous negation operator, as we will shortly see.

However, the most interesting and least extravagant of modern day semantic presuppositionalists, Burton-Roberts, follows Strawson's lead with regard to the univocality of the semantics of natural language negation. $\mathrm{He}$ argues convincingly, against the received view, that it is contradictory to maintain both that natural languages are semantically presuppositional and that they have a negation operator that cancels presuppositions, as in the examples (I)-(3). This, he says, is tantamount to inventing a second operator to mop up a set of counterexamples to the thesis that natural languages are presuppositional, a thesis which entails that their negative sentences cannot be P-cancelling. No logical theory of presupposition can include a semantic means of presupposition cancellation. B-R is surely right about this; his argument clears up a conceptual confusion perpetrated by presuppositionalists and anti-presuppositionalists alike. Semantic presupposition does not entail the semantic ambiguity of negation, quite the contrary.

He himself advocates a single negation operator which, strictly speaking, is neither $\mathrm{P}$-cancelling nor $\mathrm{P}$-preserving; it is semantically wide in scope but ' Not- $A$ is not expressive of the falsity of the presuppositions of $A$ ' (B-R I993: 33). P-preservation is essentially a semantic matter, although it is not truthconditional. B-R (I989b: I48-I 50) describes the existential presupposition of 'The $F$ is not $G$ ' as a default semantic implication and B-R (I993: 36-38) explains it as the result of an interaction of the negative sentence (which cannot cancel presuppositions) and a fundamental cognitive principle of bivalence: the proposition is tacitly affirmed by virtue of being in the domain of denial (negation) but not itself denied. This is weaker and subtler than Strawson's presupposition-PRESERVING negation operator, which, B-R (I993) shows, does not yield an internally coherent semantic account of presupposition and negation. B-R's view that the preservation of presupposition in negative sentences does not require a negation operator which itself 
encodes P-preservation is an interesting development, though not without problems of its own (even assuming that the idea of a sentential negation that neither cancels nor preserves certain entailments of that sentence is a coherent notion, something which is far from immediately apparent). ${ }^{2}$ However, for my purposes here, the details can be left aside; the common core of Strawson's and B-R's presuppositional views is that the negation operator does not (cannot) cancel presuppositions. It is this broad distinction between semantic presuppositional views and anti-presuppositional views which is relevant here.

To complete his account, B-R has to confront the fact that in the examples in (I)-(3) the negation in the first sentence, which is followed by a clause explicitly denying a presupposition, must be interpreted as cancelling that presupposition, if the examples as a whole are to be understood as consistent. This he does, by insisting that these have a special 'metalinguistic' interpretation, which is entirely a matter of pragmatics, lying beyond the expressive power of the linguistic system itself, as he puts it. The semantics of the sentence pairs in each example delivers a contradiction; for instance, in (I) that there is a king of France and that there isn't a king of France. It is this contradictory, and so unacceptable, interpretation, supplied by the language itself, which triggers the search for some other way of construing these utterances and results in the metalinguistic interpretation. I will look more closely at the phenomenon of metalinguistic interpretation in the next section. An interim and terse summing up of B-R's view at this point is the following: the P-preserving interpretation of negative sentences is given by linguistic semantics and bivalence, and the P-cancelling interpretation, required for (I)-(3), is derived by a process of pragmatic inference.

Let us move now to the opposition. I will refer to this as the 'anti-presuppositionalist' position, where this is to be understood as shorthand for the position that there is no SEMANTIC relation of presupposition encoded in natural language; the phenomena that B-R treats as semantic presuppositions are simply ordinary entailments though they often have a special pragmatic status. This is essentially the position of Grice (I98I) and of a number of linguists and philosophers, whom I shall refer to, somewhat loosely, as 'Griceans', where this is to be understood as those who advocate a pragmatic derivation of presuppositional effects. I include here

[2] B-R's presuppositional logic for natural language is bivalent with truth-value gaps; that is, presupposition failure leads not to a third truth-value, but to sentences which are simply not truth-evaluable (see B-R (I989b), especially chapter 6). However, according to his 1993 account of the intuition of presupposition-preservation under negation, a cognitive Principle of Bivalence inevitably induces the affirmation of the presupposition, since, semantically, it is not denied though it is in the domain of denial. The upshot of this is that in a case of a negative sentence with presupposition failure (e.g. 'The king of France is not wise'), that which is affirmed ('there is a king of France') is false, so the whole sentence/utterance is false, contrary to the truth-value gap predicted by B-R's presuppositional logic. (See Burton-Roberts (I993: 35-38) or the reprinting (I997: 82-85).) 
Kempson (1975), Wilson (1975), Boer \& Lycan (1976), Atlas (1977, I989), Gazdar (1979) and Horn (I985), though there are important differences of detail among them. Given the focus of this paper, I will confine myself to what they have to say about NEGATIVE presuppositional sentences for the moment.

Interestingly, Grice himself seems to have been comfortable with a position that maintains both the Russellian scope ambiguity of negation AND gives a pragmatic (implicature) account of the P-preserving understanding, which is the preferred one even when negation takes wide scope. For instance, the implication that 'there is an F' in the familiar ' The $F$ is not $G$ ' type of example is derived as a generalised conversational implicature. While the 'Gricean' views (of Atlas, Kempson, Wilson, etc.) also derive the Ppreserving interpretation pragmatically, their claim is that negation itself is semantically univocal and maximally wide in scope. ${ }^{3}$ This view of negation, clearly, accommodates our key examples since it cancels all semantic implications of the corresponding positive sentence, including its alleged presuppositions. The preferred P-preserving understanding of negative sentences is arrived at pragmatically. Horn (1989: chapter 7) refers in a general sort of a way to 'some process of pragmatic strengthening' which would yield this interpretation. This might take the form of an implicated assumption, as Grice (198I) suggests; in that paper, he gives an explicit account of the derivation of the implicature on the basis of a manner maxim of 'conversational tailoring', which I won't reiterate here. Alternatively, it may be treated as one instance of the prevalent process of relevance-driven pragmatic enrichment at the level of the proposition expressed by the utterance (see Sperber \& Wilson 1986, Carston 1988, Wilson \& Sperber I993); how this narrowing process proceeds in the negation case is discussed in section 6.2 below. Given the broad brush differences I am concerned with here (between the semantic presuppositionalist and the pragmatic presuppositionalists), I leave aside an assessment of these two different ways of cashing out the pragmatic story of P-preservation.

The two rival analyses then agree in just one respect: semantically (that is, in terms of the meaning encoded in the language system), there is a single negation operator or a single meaning for 'not'. However, they differ in every other respect: this single negation operator is quite different in its functioning, on the two views, and the respective roles of semantics and pragmatics in accounting for the P-preserving and P-cancelling cases are effectively the opposite of each other. This is perhaps made more vivid by the following

[3] Atlas (1977, I989) advocates an even more radically neutral semantics for the univocal negation operator; this is his 'sense-generality' of negation thesis. According to this, negation is semantically unspecified as to scope (whether wide or narrow) and as to its interaction with presuppositions. As a result EVERY utterance involving negation requires some pragmatic inference to determine its intended function, including cases of wide scope P-cancelling negation. 


\section{SEMANTICS / PRAGMATICS DISTINCTION}

contrasting schematic representations of the way the two approaches treat negative sentences of the form 'The $F$ is not $G$ ':

A. Burton-Roberts (semantic presuppositionalist):

Semantically: The F is not-G (P-preserving)

Pragmatically: $\operatorname{not}[$ The $F$ is $\mathrm{G}] \quad$ (P-cancelling)

B. 'Griceans' (anti-presuppositionalists):

Semantically: not [the F is G] (P-cancelling) ${ }^{4}$

Pragmatically: The $\mathrm{F}$ is not-G (P-preserving)

This apparent symmetry should not mislead us, though, into assuming that the P-cancelling representations here (pragmatically derived in the one case, semantic in the other) are in fact identical. While this is descriptive truthfunctional negation on the Gricean view, it is a special (pragmatically derived) metalinguistic negation on B-R's view. I will briefly outline the phenomenon of metalinguistic negation now, highlighting those aspects of it that have a bearing on the subsequent discussion. ${ }^{5}$

\section{Metalinguistic Negation}

Both B-R and Horn assimilate examples (I)-(3) into the class of metalinguistic negation (MN) and I too call on it in my proposed account of these examples. We three construe this use of negation rather differently from each other.

\section{I The standard view}

Here's a set of cases that everyone agrees are instances of metalinguistic negation:

[4] The semi-formal representation here with the 'not' placed outside the positive sentence reflects the one-place propositional connective of the Fregean logical system. Horn prefers the Aristotelian predicate denial formulation and has rather good arguments for it, so an alternative representation of this level might be [The $F$ is-not $G$ ] as a way of capturing the idea that 'not' is a mode of predication. Nothing hangs here on the difference in the formulations since both encompass so-called presupposition-cancellation.

[5] Recently, there has been considerable discussion about whether natural language determiners other than 'the' are 'presuppositional'. The issue concerns whether the semantics of 'every' is equivalent to the classical logical universal quantifier or is stronger in that it incorporates an existential implication. Cases such as the following seem to suggest that it does, since the non-existence of any American king prompts the intuition that these are truth-valueless (undefined):

(i) Every American king lived in New York.

(ii) Every American king didn't live in New York.

Many of the issues addressed in this paper carry over to these examples, in particular, the interaction of negation with the apparently presuppositional subject noun phrase and the fact that the most natural interpretation of (ii) is metalinguistic. See Lappin \& Reinhart (I988) and Lasersohn (I993) for non-semantic accounts of how the existential constraint on 'every' (and other strong determiners) arises in use. 
(4) (a) The points aren't at different locuses; they're at different loci.

(b) We're not halfway there; we've got halfway to go.

(c) Poor old Mr Dean's not a bachelor; he's an unmarried man.

(d) I won't deprive you of my lecture on negation; I'll spare you it.

(e) She hasn't read some of Chomsky's books; she's read everything he ever wrote.

(f) Bob isn't either neurotic or paranoid; he's both!

These have all the properties of the most often cited types of cases: (i) they consist of a negative sentence followed by a 'rectification' clause; (ii) taken descriptively they are (truth-conditional) contradictions; (iii) readers may be garden-pathed, in that their first interpretation of the negative sentence is descriptive and when they process the second clause they find they must 'go back' and reanalyse the negative sentence as metalinguistic; (iv) if read aloud, these examples would tend to receive the so-called contradiction intonation contour (involving a final rise within the negative clause), with contrastive stress on the offending item and its correction in the second clause.

These examples with these properties are perfectly representative of the sort of example given by B-R (I989a, b) and reasonably representative of the type of example given by Horn (1985, I989: chapter 6). The negation operator itself is said by Horn to be interpreted as 'I object to U', where U is a prior (or, perhaps, potential) utterance of the corresponding positive sentence (e.g. 'She's read some of Chomsky's books' in the case of (4e)). The aspect of the utterance that is objected to is something other than its truthconditional content: morphology in (4a), an attitudinal or perspectival element in (4b), stereotypical connotations in (4c), a conventional implicature in (4d) and generalised conversational implicatures in (4e) and (4f). So the meaning that the negation operator has in these examples is held to be quite distinct from the descriptive truth-functional meaning which negation semantically encodes; this derived meaning is pragmatically inferred.

\subsection{A different view}

I have argued, in Carston (1994) and Carston \& Noh (I995), that in fact none of the standardly cited properties is necessary. I won't repeat those arguments here, except for presenting one type of example which will prove relevant to later discussion. Consider the following:

(5) (a) Maggie's not patriotic or quixotic; she's patriotic and quixotic.

(b) Maggie's patriotic and quixotic; she's not patriotic or quixotic.

(6) (a) I won't deprive you of my lecture on negation; I'll spare you it.

(b) I'll spare you my lecture on negation; I won't deprive you of it.

The difference between the (a) and (b) cases is simple and obvious: the two 
clauses are presented in opposite order. The (a) versions are instances of the general pattern of cases given above in (4), with the various properties just outlined, including contradictoriness and garden-pathing potential. What, if any, effect does reversing the order have, as in the (b) cases? It clearly doesn't alter their contradictoriness (' $\mathrm{P}$; not $\mathrm{P}$ ' is no less contradictory than 'not $\mathrm{P}$; $\left.\mathrm{P}^{\prime}\right)$ or the metalinguistic nature of the negative utterances:

(7) A: Don't deprive us of your lecture on negation.

B: I'll spare you my lecture on negation; I won't deprive you of it.

However, in the (b) cases, since the correction clause is processed first it is part of the context in which the negative clause is processed so it is very unlikely that there is any garden-pathing, requiring double processing of the negative sentence. The metalinguistic nature of this utterance of the negative sentence will be recognised on the first pass through the utterance, without any preliminary stage at which it is analysed descriptively. The first clause makes it clear to the hearer that the speaker does not dispute the truthconditional content of the positive counterpart of the negative sentence (that Maggie is patriotic or quixotic, in (5b), and that the speaker won't be giving her lecture on negation in (6b)), since the first clause either expresses the same proposition as the positive utterance would (in (6b)) or a stronger one that entails it (in (5b)). The point, then, is that the negative clause will be processed straight off as a case of metalinguistic use, something that neither Horn nor B-R allow for. While this simple observation is relevant here, in that it undercuts much of what has been taken to be typical of metalinguistic negation, its real interest will emerge later (in section 6) when we look at reversed presupposition-denial cases.

I will mention briefly now the positive aspects of my account of metalinguistic negation. They are: (i) the only essential property of these cases is that (some, at least) of the material falling within the scope of the negation operator is to be understood as 'echoically used' in the sense of Sperber \& Wilson (I986), Wilson \& Sperber (I988, I992), and (ii) the negation operator itself acquires no special pragmatic meaning such as 'I object to U' (Horn I985: I36); in all these cases it is interpreted as standard truth-functional negation. Let's take each of these in turn.

A representation is used echoically when it attributes some aspect of its form or content to someone other than the speaker herself at that moment and expresses an attitude to that aspect. The attribution may be explicit or implicit, and the expression of attitude may be explicit or implicit. Hence all of the following can involve echoic use:

(8) (a) A good time to buy, he said.

(b) A good time to buy, I don't think.

(c) A good time to buy, indeed. 
(d) She eats tom[eiDouz].

(e) I don't eat tom[eiDouz]; (I eat tom[a:touz].)

In (8a) the attributive nature of the utterance is made explicit; the speaker may be merely reporting someone's utterance or she may be echoing the proposition that it is/was a good time to buy in order to express (implicitly) her own attitude to it, an attitude of either an endorsing or a dissociating nature. In (8b) a dissociating attitude is made explicit. In (8c) both the attribution of the propositional content and the attitude to it are implicit; when that attitude is dissociative (which would have to be pragmatically inferred) the utterance is a case of irony (see Wilson \& Sperber I992). In the last two examples, what is attributed is a formal aspect of the utterance, here phonetic form; in (8d) the attribution (presumably to the person referred to by 'she') and the speaker's attitude are implicit. In (8e), a standard case of metalinguistic negation, the attribution is implicit while the attitude of dissociation is made perfectly explicit by the use of the negation. This, I have argued, is the only essential property of metalinguistic negation.

Both Horn and B-R acknowledge the quotational or metarepresentational nature of material in the scope of the negation operator. Horn $(1989,392)$ talks of the negation operator and the material in its scope as 'operating on different levels'; B-R (I989b: 235) homes in more closely on this feature when he writes of negation operating 'on the MENTION of a proposition previously used - i.e. operating on the speaker's QUOTATION of a previous speaker's USE of [a sentence]'. However, neither makes much of this; they tend rather to emphasise such features as those given in the previous section, while, in my view, it is the implicit (that is, not linguistically signalled) metarepresentational nature of material in the scope of the negation which is the single essential and unifying property of cases of metalinguistic negation. B-R takes the fundamental unifying property of all cases of metalinguistic negation to be their literal contradictoriness. As we will see later, this is crucial to his metalinguistic account of the presuppositiondenials and, more fundamentally still, to his semantic stance with regard to presupposition. This is taken up in section 5 .

The probably more contentious part of my view is that the negation operator here is not interpreted any differently from the negation in a descriptive (non-metalinguistic) case. That he finds this inimical has been made very clear by Horn, who insists that, in the metalinguistic cases, negation is understood as a non-truth-functional operator, expressing objection to an utterance, and 'irreducible to the ordinary internal truthfunctional operator' (Horn (I985: I32; 1989: 434). As far as I can see, B-R goes along with this, although he is not fully explicit on the point; the only truth-functional negation operator he can countenance in his presuppositional semantics is one that does not cancel presuppositions, so in the presupposition-denial cases, negation must be receiving some other in- 


\section{SEMANTICS / PRAGMATICS DISTINCTION}

terpretation. Horn's conviction comes from the fact that a truth-functional negation, by definition, takes as its argument a (truth-evaluable) proposition, while the target of negation in the metalinguistic cases can be any one of a ragbag of formal and other non-truth-conditional properties of an utterance. On the surface this does seem persuasive, but there are some considerations, which I'll briefly indicate now, that mediate against it. (These are presented somewhat more fully in Carston I994 and Carston \& Noh 1995.)

Quotations, echoes and other representations employed for purposes other than referring to or describing aspects of situations in the world are very common elements of verbal communication generally, by no means confined to negations. As shown in the examples in (8), this non-descriptive use of a representation may or may not be explicitly signalled. When explicitly signalled, by, for example, a verb of saying or quotation marks, there seems to be no problem in grasping the proposition(s) falling in the scope of truthfunctional operators:

(9) (a) Americans say tom[eiDouz] and Brits say tom[a:touz].

(b) The army slaughtered everyone in the village or, according to them, 'ethnically cleansed' it.

(c) The correct plural of 'mongoose' is not 'mongeese' but 'mongooses'.

We have here a conjunction, a disjunction and a negation; within the scope of each of these operators some part of the representation is used nondescriptively. However, there seems to be no temptation to say that, as a result, these operators must be understood as having some interpretation other than their standard truth-functional meaning. The truth-conditions are clear enough in each case; for instance, (9a) is true if and only if it is the case that Americans pronounce the word in question as tom[eiDouz] and the British pronounce it as tom[a:touz].

In the next set of examples, we are not given an encoded indication that there is an element of non-descriptive or echoic use; this has to be pragmatically inferred:

(Io) (a) Americans eat tom[meiDouz] and Brits eat tom[a:touz].

(b) The army annihilated, or ethnically cleansed, the village.

(c) They're not mongeese but mongooses.

The question to ask at this point is whether or not it is reasonable to suppose that these operators, which are, let us assume, semantically truth-functional, lose their truth-functionality as a result of the absence of an explicit signal that material in their scope is being used non-descriptively. Surely not. What sort of causal connection could there be between, on the one hand, the move from explicit to implicit echoic use of a representation and, on the other, a fundamental change in the interpretation of the logical operator within whose scope the representation lies? I contend that there is none and that the 
interpretation of the operators in (IO) is the same as that in (9): ordinary descriptive truth-functional conjunction, disjunction and negation.

A further observation mediating against Horn's 'I object to U' interpretation of negation in the metalinguistic/echoic cases is that it is very difficult to see how it will accommodate the variety of encodings of negation that we can find in such cases, including 'not at all', 'not any more', 'not ever', 'not anywhere', 'neither ... nor', 'it is unlikely that', 'I doubt that'; this is discussed in Carston (1998: chapter 5).

\subsection{Differences between Horn and Burton-Roberts on metalinguistic negation}

While the properties given in section 3.I are typical of the examples Horn gives when he is focusing on explicating metalinguistic negation (MN), it is instructive to look at other parts of his extensive writing on negation where he occasionally calls on metalinguistic negation to explain an example in the context of some other issue altogether. For instance, he gives the following (attested) examples in the context of a discussion of the interaction of the existential quantifier with negation:

(I I) (a) A sociopath wouldn't get through the first ten minutes of my films. They are too slow. Someone isn't killed in the credits.

(from a newspaper interview with Brian de Palma)

(b) She swung round, she took two strides to him, waiting for someone to stop her, but someone didn't.

(from John Le Carre's The Little Drummer Girl)

(Horn 1989: 494, examples (4I))

It is often remarked that negation is not interpreted as taking wide scope over the existential quantifier and that this contrasts with its interaction with the universal quantifier where such an interpretation is available (e.g. 'Everyone isn't happy'). However, in the examples in (I I ), the existential quantifier does fall within the scope of negation. Horn's claim is that these are cases of 'metalinguistic or second-instance negation' (I989: 496). He reinforces this by giving a range of further examples of the same sort where positive polarity items fall in the scope of the negation, this being a standard diagnostic for a metalinguistic use of negation.

What is of interest to me here is that these examples have few of the properties mentioned above as characteristic of $\mathrm{MN}$ : there is no previous utterance being echoed (though they are echoic in the wider sense expounded above); there is no follow-up (correction) clause; there is no descriptive contradiction; there is no double processing of the negative sentence. B-R seems to see these as essential properties of metalinguistic negation. He takes contradictoriness, in particular, to be a defining property of metalinguistic negations; his account of the presupposition-denial cases as inevitably cases 
of MN hangs on this, as does his criticism of Horn's anti-presuppositionalist position.

It seems, then, that they are not dealing with the same phenomenon after all; the set of examples that falls under B-R's conception of $\mathrm{MN}$ is a subset of the set that falls under Horn's conception. This difference between them is not confined to examples involving the existential quantifier; consider the following statement from Horn: ' ... any negation which takes scope over a [sentential] conjunction, disjunction, or conditional must be metalinguistic' (Horn 1989: 476). According to him, the following examples have to be interpreted metalinguistically (that is, as expressing unwillingness to assert a proposition rather than as asserting the negation of that proposition):

(I2) (a) It's not the case that Chris won and Sandy lost.

(b) It is not the case that if $\mathrm{X}$ is given penicillin he will get better; (it might very well have no effect on him).

We may or may not agree that these are necessarily metalinguistic. Horn is forced to take this line by his treatment of descriptive negation as a mode of predication (predicate denial) rather than as a sentential operator. However, the reason for pointing it out here is merely to highlight some of the differences between Horn and B-R with regard to the way they view metalinguistic negation and the range they give to it. For B-R (I 2a) would not qualify as MN unless it occurred as follows:

(I2') (a) It's not the case that Chris won and Sandy lost; Sandy lost and Chris won.

where the follow-up clause is semantically equivalent to the proposition falling in the scope of the negation and the whole therefore constitutes a contradiction. For Horn, on the other hand, this particular follow-up clause gives just one possible ground for the $\mathrm{MN}$ (for the objection to the positive conjunctive utterance); other grounds would be the falsity of the proposition that Chris won or the falsity of the proposition that Sandy lost or the falsity of both of them. When Horn says, as he frequently does, that $\mathrm{MN}$ is 'a device for objecting to a previous utterance ON ANY GROUNDS WHATEVER ...' (I989: 363 , my emphasis) he appears to mean it literally. While the examples that are most often presented to illustrate $\mathrm{MN}$ involve an objection to some nontruth-conditional aspect of an utterance, the grounds for $\mathrm{MN}$ can be the falsity of any of the entailments (presuppositional or not) of the proposition expressed by that utterance.

What emerges from this is that for Horn, as for me (see Carston 1994), it is possible for one and the same negative sentence (with or without a followup clause) to be understood as descriptive in one context and as metalinguistic in another. This depends, in my view, on whether or not the material within the scope of the negation is being used descriptively or echoically. For B-R, 
on the other hand, these options appear to be mutually exclusive. If we were to confine our attention to examples such as those in (4), he might seem to be correct, because these cases, which focus on some aspect of linguistic form, are indeed contradictory if understood descriptively. It is the, rather idiosyncratic, properties of these cases that B-R depends on when he contends that if presupposition-denials (e.g. (I)-(3)) are understood metalinguistically, as Horn says, then that is because they can ONLY be understood in that way. As with the examples in (4), taking them descriptively yields a contradiction. The essential point for B-R is that this provides strong evidence for his semantic presuppositional account since it is only on this account that these examples are found to have these characteristic properties of $\mathrm{MN}$, thereby making it possible to give a unified account of the class of metalinguistic negations. It follows from this view that in order to be consistent we must all convert to semantic presuppositionalism.

In the next section I will complete this outline of B-R's position and review the dilemma that he claims Horn's mixed allegiances lead him into.

\section{The Burton-Roberts package and Horn's dilemma}

\section{I The interdependence of metalinguistic negation and presupposition?}

The last section pointed up some differences in the range of cases that B-R and Horn admit into the class of metalinguistic negation. The following cannot be cases of $\mathrm{MN}$ for B-R because they are not semantic contradictions:

(I3) (a) She didn't flaunt the rules; she flouted them.

(b) He doesn't need four mats; he needs more fats.

(c) I didn't put him up; I put up with him.

Note that they have all the other characteristic properties of the standard cases of metalinguistic negation: they are most easily contextualised as rejoinders to (corrections of) an utterance of the corresponding positive; the negative utterance is followed by a rectification clause; if spoken they would be naturally intoned with the 'contradiction' contour and take contrastive stress on the offending item and its replacement. The representation of the offending item is readily taken to be echoic, the essential property, I have argued, of metalinguistic cases. They may or may not garden-path a reader; this is always possible when echoic or metarepresentational use is not signalled explicitly, though in an appropriate context their non-descriptive nature may be accessed by the reader/hearer on a first pass. Kempson (I986), Foolen (I99I) and Horn (I989, I992) all take examples of this sort to be metalinguistic; B-R alone excludes them.

The examples in (I3) seem to involve linguistic mistakes (perhaps slips of the tongue) so that the correction clauses bear no particular informational relation to the presumed positive utterances. Consider now the following 
examples where there is a closer informational relation between the proposition expressed in the correction clause and the proposition expressed by the presumed positive utterance or thought:

(I4) (a) A: Are you going to sack him?

B: I'm not going to sack him; I'm going to kill him.

(b) A: That letter must reach Bill by tomorrow at the latest. I hope you've put it in the mail.

B: I haven't put it in the mail; I've delivered it to him by hand.

The rhetorical nature of these is the same as that which Horn and B-R point out when discussing the standard cases of $\mathrm{MN}$; they are in the format of the original examples in (4) and they have the special effects that come from first interpreting the negative sentence as wholly descriptive and then, on the basis of the rectification clause, having to backtrack and reanalyse as echoic. (I 4a), which occurred on a television sitcom and raised a laugh from the audience, is a typical garden-pathing joke. But these are not cases of contradiction so, for B-R, they cannot be cases of metalinguistic negation, for a literal contradiction, provided semantically, is required to provide the rationale for the pragmatic reanalysis, on his view (B-R I989b: 232, 235). Killing someone does not entail sacking him; delivering a letter by hand does not entail putting it in the mail. The property these examples, and countless others we could construct, have is that the proposition expressed in the correction clause is conceived of as stronger (in the sense of having more contextual implications) than the proposition that the positive counterpart of the negative sentence would express: killing someone is more extreme than sacking him, delivering a letter by hand on a particular day is a better means of ensuring it reaches its destination by the next day than is putting it in the mail. The scale of degrees of informational strength here is pragmatic rather than semantic. I have argued at greater length in Carston (1994) that it is a mistake to try to pin $\mathrm{MN}$ down to a phenomenon with any particular semantic property when taken descriptively, as B-R does; it is a pragmatic matter and as such deeply sensitive to the particularities of context. I think these examples demonstrate this point very well; they are patently cases of $\mathrm{MN}$, cases that even have the special rhetorical effects that have all too often been taken to be the essence of the phenomenon.

$\mathrm{B}-\mathrm{R}$, however, is committed to the semantically contradictory nature of instances of metalinguistic negation; this requirement is the foundation of the edifice he subsequently builds, in which a presuppositional semantics and metalinguistic negation are mutually reinforcing. Horn and many others are in agreement with him that the presupposition-denial cases are instances of $\mathrm{MN}$ :

(I5) A: The President of New Zealand is young.

B: The President of New Zealand is not young; New Zealand doesn't have a president. 
This is not a mere interpretive possibility for B-R but a necessity, since these are cases of semantic contradiction on his presuppositional account: taken descriptively, B would be communicating both that there is a president of New Zealand and that there isn't one. On the basis of his claim that the unifying property of $\mathrm{MN}$ is its logical contradictoriness, B-R is able to adduce strong support for his presuppositional semantics:

Since I, with Horn and others, take the whole Set III [i.e. the presupposition-denial examples in (I)-(3) together with the examples in (4)] to constitute a homogeneous set of metalinguistic negations, it is of some importance to capture the generalisation that the motivation for the pragmatic analysis invited by this use of negation stems from the need to resolve a truth-conditional contradiction. On a presuppositional semantics, and only on a presuppositional semantics, this generalisation holds good of ALL the cited examples.... A PROPERLY GENERAL AND EXPLANATORY ACCOUNT OF METALINGUISTIC NEGATION ITSELF IMPLIES A PRESUPPOSITIONAL SEMANTICS.

(B-R I989b: 235, my emphasis)

I have just cast some doubt on the generalisation that MNs are contradictions. While it is an interesting fact that many of the most often cited cases of $\mathrm{MN}$ are semantic contradictions, there is no evidence that the properties of this subset of cases of $\mathrm{MN}$ should be taken as embodying the essence of MN. Their obvious contradictoriness makes their metalinguistic interpretation particularly salient, even out of any context, and so they are especially useful for exemplificatory purposes, but we shouldn't let their salience and effectiveness mislead us into thinking that their particular features define a natural class (see Carston (I994: 3 I9) for further discussion). In section 5, I will show that, whatever the case may be for MN generally, the evidence is strong that presupposition-denials are not contradictions. As should be clear from the foregoing, if this is true it brings about a total unravelling of the tightly interwoven threads of B-R's story. We are not there yet, though; we need to draw the other participants, especially Horn, back into the tale.

\subsection{Horn's (alleged) dilemma}

'Gricean' accounts of the presupposition-denial cases take them to be adequately covered by the semantics of negation, which is P-cancelling and so does not require any pragmatic inferential work. This is a logically consistent view, but, as B-R, Horn and other have pointed out, it completely fails to account for the universally agreed sense of markedness, the special effects, that these cases have, and the equally agreed view that the most natural contextualisation is that on which they are taken as rejoinders to a (potential) utterance of the corresponding positive. 
However, Horn (1985, I989), who certainly counts himself among the antipresuppositionalists and advocates a semantically wide scope predicate denial negation, seems to think (I)-(3) are metalinguistic negations. Indeed he begins his influential 1985 paper on metalinguistic negation with the standard example of an 'external' or 'marked' negation, (I) above, repeated here,

(I6) The king of France is not bald (because) there is no king of France.

and claims that both the existing semantic ambiguity accounts and the 'Gricean' univocality accounts in terms of a wide scope (P-cancelling) truthfunctional negation operator are seriously flawed. He proceeds to demonstrate a range of cases of negative utterances which seem to require a special metalinguistic use of the negation operator (examples such as those in (4)) and claims that, while negation may be univocal and truth-functional as regards its semantics, it is pragmatically ambiguous. Horn's important claim for the topic of this paper is that 'external, presupposition-cancelling negation is part of [this] wider phenomenon characterized as the use of negation to signal ... the speaker's objection to the content or form associated with a given utterance' (Horn I985: I22).

On the face of it, Horn's position does seems to entail a pointless redundancy: P-cancellation can apparently be achieved in two ways, the one semantic and the other pragmatic. In addition to the intrinsic undesirability of such redundancy in a theory, it leaves an explanatory gap: if the bare output of semantics gives you P-cancellation (for free as it were) how does P-cancellation ever get to be a case of metalinguistic negation, which both Horn and B-R agree it is? Given this semantics, it is only P-preservation that HAS to be derived pragmatically. Horn avoids putting the different parts of his position together and looking at their implications, so that he does not appear to notice this issue. However, the analysis of presupposition-denials, such as (I)-(3), that I offer in section 6 is one which accommodates the fact that they are typically interpreted as cases of metalinguistic (or 'echoic') negation while, nonetheless, employing a negation operator which is semantically P-cancelling. If this analysis is right, it shows that, after all, Horn's position, drastically under-articulated though it is, is essentially right.

A dilemma created by a redundancy is one thing, but a dilemma forced by incoherence is another matter, a far more serious one, that urgently calls for a choice between the opposed positions. It is this that B-R charges Horn with:

Horn's dilemma in essence was this: having noticed that such 'Pcancellations' intuitively and functionally cohere with other cases of an independent pragmatic phenomenon of metalinguistic negation, Horn (1985)... wished to include P-cancellation among the functions of his pragmatic, metalinguistic negation. But this, I argued [in B-R I989a, b], Is ONLY EXPLANATORY AND COHERENT, AND INDEED POSSIBLE, IF P-CAN- 
CELLATION IS NOT ACHIEVED IN THE SEMANTICS [my emphasis]. Now, theories in which P-cancellation is not achieved in the semantics are by definition SEMANTIC THEORIES OF PRESUPPOSITION. But Horn (I985) wished to join the anti-presuppositionalists in denying the existence of semantic presupposition in any shape or form.

(B-R I990: 460-46I)

While he disagrees with the 'Gricean' position, set out in section 2, B-R accepts it as an internally consistent and coherent position. He considers Horn, on the other hand, to be trying to straddle two different positions with a result of incoherence. The claim is that Horn's various commitments pull him in two opposing, irreconcilable directions: he is simultaneously an (avowed) anti-presuppositionalist and an (unavowed) propresuppositionalist. These horns are not equally explicit or salient in Horn's work, of course. While he is explicit about his opposition to semantic presupposition, his pro-presuppositionalism is an unrecognised consequence of his commitment to a metalinguistic negation account of the presupposition-denial cases. Again, it is a result of my analysis in section 6 that there is no inconsistency in both refusing to take up the semantic presupposition calling and agreeing that the negation in the presuppositiondenial cases is standardly interpreted as operating over metarepresented material, an interpretation that inevitably involves pragmatic inference.

According to $\mathrm{B}-\mathrm{R}$, the metalinguistic account involves a process of pragmatic reanalysis which is only possible 'if $\mathrm{P}$-cancellation is not achieved in the semantics', that is, it requires a prior semantico-logical analysis on which negation is presupposition-preserving. It follows that the presupposition relation itself must be semantic; a unitary account of metalinguistic negation implies a presuppositional semantics. Certainly, if B-R were right about this, Horn's position would be untenable. I shall argue, however, that he is not right, that he has created the appearance of a dilemma by setting up an unwarranted and unargued-for body of precepts about the nature of semantics and pragmatics and the relation between them. In particular, I shall take issue with his assumption that the result of a process of pragmatic inference must be a representation which accounts for a distinct range of cases from those that the underlying sentence semantics covers. I will take up this 'semantic-pragmatic disjunction thesis', as we may call it, in section 7 .

The following schematic summary highlights the differences between the three distinct positions we now have.

\begin{tabular}{|c|c|c|c|}
\hline & B-R & 'Griceans' & Horn \\
\hline semantic & + & - & - \\
\hline presuppositions & & & \\
\hline negation P-cancelling & - & + & + \\
\hline P-denials (I)-(3) & & & \\
\hline metalinguistic & + & - & + \\
\hline
\end{tabular}




\section{5. 'PRESUPPOSITION'-DENIALS: NEITHER CONTRADICTORY NOR} NECESSARILY METALINGUISTIC

It follows from B-R's overall presuppositional theory that P-denial cases should be descriptive contradictions. Much hangs on the correctness of this conclusion, including at least the following propositions: (i) P-denials are necessarily metalinguistic (they fall outside the descriptive power of the language system); (ii) the correct analysis of negations of 'presuppositional' sentences requires a negation operator that is semantically incapable of cancelling presuppositions; and so (iii) consistency demands that anyone who includes P-denials in the class of $\mathrm{MN}$, for instance, Horn, must embrace a semantic account of presuppositions. If the contradiction claim is incorrect then all of this collapses; indeed, since the claim is a consequence of the general presuppositional theory, it must be bad news for some, at least, of the premises of that theory. In this section I do little more than gather together evidence, already presented in different places by various writers (pro- and anti-presuppositionalist), which mounts a very strong case for the noncontradictory nature of the 'presupposition'-denial cases. I draw on Kempson (I986), Seuren (1988, I990), Horn (I990) and Turner (1992).

\section{I Evidence against the contradictoriness of P-denials}

As a first observation, notice that the 'correction' clause in the 'presuppositional' cases (as opposed to the 'standard' cases, given in (4)) is always a negative; it is of course the negation of a presupposition (or, as an anti-presuppositionalist would prefer to say, of an 'entailment') of the positive counterpart of the negative sentence under consideration. This is interesting because it indicates that what the 'correction' clause is doing is making it clear to the hearer which one of the truth-conditions/entailments of the positive sentence is to be taken as the grounds for the negation. This is not a point against B-R's semantic contradiction view since, while both presuppositions and ordinary (strong) entailments contribute to truthconditions, presuppositions, on his view, are a special sort of truth-condition in that they are not cancelled under negation. On the view I would argue for, however, at the descriptive (semantic) level the 'correction' clause in the 'presuppositional' cases is more akin to the 'specification' clause in the following cases:

(I7) (a) I didn't pass all my exams and get a good job; I only passed five out of the six.

(b) He didn't butter the toast with a knife in the bathroom at midnight; he used a toothbrush.

What the follow-up clauses do in these examples is specify which of the entailments of the corresponding positive sentence is false and so make 
explicit the grounds for the negation in the first clause. There are, of course, strongly felt intuitive differences between these examples and the P-denials; the reader/hearer is not so likely to 'misinterpret' the negative sentence on a first pass as $\mathrm{s} /$ he is in the case of a P-denial, so these do not feel as marked as the P-denials. However, this difference is consistent with an antipresuppositionalist view, I would argue, in that it can be explained as purely a matter of pragmatic processing (rather than anything to do with the semantics of the sentences). In (I 7a) there is no pragmatic narrowing of the negation to one of the conjuncts, whereas in the presuppositional cases there is a very common process of narrowing to exclude the presupposition ( $\mathrm{P}$ preserving negation); while the existential implication is standardly backgrounded relative to the other entailments, the two conjuncts in (I 7 a) are equally foregrounded so that neither is more likely to be the focus of the negation than the other. ( $\mathrm{I} 7 \mathrm{~b})$ is interesting in that it seems to fall somewhere between (I7a) and P-denials with regard to markedness/garden-pathing. Abstracting away from particular directives given by particular stress patterns, the most natural, though not inevitable, interpretation is the one on which the final constituent, 'at midnight', is the focus of the negation, an analysis which has to be revised in the light of the follow-up clause. My point is that all three cases (the two in (I 7) and the P-denial examples) have a clause following up the negative sentence which makes explicit which of the entailments of the corresponding positive is the false one and this is consistent with a wholly descriptive interpretation.

I shall move on now to some groups of data which are aimed at sowing increasing doubt about the alleged contradictoriness of the P-denials and, finally, at showing it to be simply wrong. The general strategy is to take 'standard' cases of metalinguistic negation (such as the examples in (4)), show that they have some property, and then check the P-denials for the same property, revealing that they do not have it. The property in question obviously has to be one that we should expect a descriptive contradiction to have. Consider the following examples (adapted from Seuren (I988: 195) and Horn (I990: 498)).

(18) (a) !It's not true that he's picking up the kids; he's picking up the children.

(b) !It's not true that she's pleased with the outcome; she's thrilled about it.

(c) !It's not true that we saw some hippopotamuses; we saw some hippopotami.

(d) !It's not true that he's my father; I'm his daughter.

(e) It's not true that the king of France is bald; there is no king of France.

Here the phrase 'it's not true that' has replaced 'not', the idea being that the explicit occurrence of the word 'true' should make a metalinguistic 
interpretation considerably more difficult to get at, as it keeps the reader/hearer in the realm of directly truth-conditional (literal/descriptive) representation. Assuming agreement with regard to the judgements marked by '!', it does seem that there is difficulty in interpreting ( $18 \mathrm{a}-\mathrm{d})$ : there is a conflict between the explicitly expressed interest in what the truth of the matter is and the subsequent pair of clauses which, if treated truthconditionally, as is apparently required, are contradictory. This is not the case for (I8e) which is fine: the explicitly encoded concern with how things are with the world is apparently followed by a perfectly consistent description of how things are.

The same results would pertain for paraphrases using 'it is false that P' and some readers might find this paraphrase more effective in prompting the intuitions I am trying to elicit here. There may, however, be some people who are not impressed by this, who would say that (I8a-d) can be interpreted quite readily, as something like 'It's not okay/right/appropriate to say ...'. Such people, I would claim, are understanding 'true/false' as loosely used, as not restricted to literal truth and falsehood (correspondence or noncorrespondence to the way things are in the world) but as communicating something like 'okay to say/not okay to say'. However, such a loose interpretation is not necessary for ( $\mathrm{I} 8 \mathrm{e}$ ) which is interpretable as involving absolutely literal use of 'true/false'. There does seem to be a genuine distinction here between the truly contradictory metalinguistic cases and the P-denials: having checked the intuitions of several groups of students, I have found that many people who find the metalinguistic negation examples in (4) quite acceptable do not find these 'not true/false' cases in (I 8a-d) acceptable, and that those (few) who find the 'not true/false' cases acceptable agree that they are not as immediately okay as the plain 'not' cases.

A further indication against the contradiction account comes from a point made by Kempson (I986: 85) concerning the possibility of an evidential interpretation of the second clause.

(I9) (a) He didn't see the sign: he was looking the wrong way.

(b) We didn't see some mongeese; we saw some mongooses.

(c) She didn't eat some of the cakes; she ate all of them.

(d) I'm not his daughter; he's my father.

(e) The king of France isn't bald: France doesn't have a king.

(f) She hasn't stopped drinking: she has never been a drinker.

Descriptively used negations, like descriptively used positives, are often followed by a clause which provides evidence for the belief expressed in uttering the first clause. (I9a) is a clear case of this: that he was looking the wrong way provides evidence for my belief/assertion that he didn't see the sign. However, when we move to (Igb-d), some of the cases standardly cited as readily giving rise to a metalinguistic interpretation, we find the second clause does not have this function. The fact that we saw some mongooses is 
not evidence that we didn't see some mongeese; even more clearly, the fact that she ate all of the cakes is not evidence for the belief expressed by the preceding negation, but is, in fact, strong evidence for its opposite, that she HAS eaten some of the cakes, and the same goes for (I9d). The evidential relation is one that is rooted in the way events and states of affairs connect up in the world, in temporal, causal and other relations to each other. It is not surprising that this is not how the metalinguistic negations and their follow-up clauses are understood, because they are, precisely, not making statements about the way things are in the extra-linguistic world. What then of the P-denials in (I9e-f)? As with (I9a), an evidential relation is readily taken to hold between the second clause and the first. The fact that France doesn't have a king is excellent evidence in support of the contention that the king of France isn't bald. In line with this, these two cases, like (I9a) and unlike the unequivocally metalinguistic cases, can be conjoined by a causal connective such as 'because' or 'since', a point which I leave the reader to check, and which is taken up again at the end of section 5.2.

A final piece of evidence (not noted by anyone else to my knowledge) against the logical contradiction idea is that the very property that led to the standard metalinguistic cases being called 'paradoxical negations' does not seem to extend to the 'presupposition'-denial cases. The more general property lying behind this is that for any two descriptive statements, $\mathrm{P}$ and $\mathrm{Q}$, which are contradictory, whether involving negation or not, each entails the negation of the other:

(20) (a) She murdered him; he's still alive. (P; Q)

(b) If she murdered him he is not still alive.

(If $\mathrm{P}$ then not Q)

(b') If he is still alive she didn't murder him. (If $\mathrm{Q}$ then not $\mathrm{P}$ )

As Horn (I989: 43 I-432), following Cormack (I980), points out, the standard metalinguistic negations seem to be paradoxical because their positive counterparts are entailed by their correction clause. That is, given the schematic representation of these examples as "Not R; Q", the following seems to be the case "Since/if Q, then R":

(2I) (a) I'm not happy; I'm ecstatic.

(a') Since/if I'm ecstatic, I'm (certainly) happy.

(b) I'm not his child; he's my father.

(b') If he is my father then I am his child.

(c) The king of France isn't bald; there isn't a king of France.

(c') !Since there isn't a king of France, the king of France is bald.

(d) Kim doesn't regret inviting Bob to her party; Bob gatecrashed/she didn't invite him.

(d') IIf Kim didn't invite Bob to her party then she regrets inviting him. 
(2Ia) and (2Ib) exhibit the same property as the examples in (20), a consequence of being descriptive contradictions. (2Ic) and (2Id), on the other hand, do not; in fact, they seem to have the contrary property in that this very manipulation gives rise to a contradiction, as is the case for any other instance of denying an entailment:

(22) (a) The king of France isn't bald; he has long black hair.

$\left(a^{\prime}\right)$ !If the king of France has long black hair then the king of France is bald.

(b) Kim doesn't regret inviting Bob to her party; she is glad he came.

(b') !If Kim is glad that Bob came to her party she regrets inviting him.

The evidence, then, overwhelmingly, is that the juxtaposition of a negative 'presuppositional' sentence with a sentence which negates its (or one of its) presupposition(s) does not constitute a semantic contradiction. This is a serious problem for B-R's semantic 'presupposition' position. Not only is it false that 'a properly general account of metalinguistic negation implies a presuppositional semantics' (see section 4.I) but, worse than that, if he is right in claiming that it is only on a presuppositional semantics that (I)-(3) are predicted to be contradictory and, as it now seems, this is a false prediction, his semantics is in trouble. However strong his other arguments for a presuppositional semantics may be, he has a major problem on his hands in accounting for (I)-(3).

Note that one problem that is NOT created by the non-contradictory nature of these examples is a puncturing of the claim that the unifying property of $\mathrm{MN}$ is its contradictory nature. This claim has already been shown to be incorrect (see section 4.I); there are many examples of MN, in addition to the presupposition-denial cases, which are not semantic contradictions. Furthermore, as I'll show in the next section, it is not inevitable that P-denials are interpreted metalinguistically.

\subsection{Are 'presupposition'-denials necessarily metalinguistic?}

As discussed above, B-R's account is a package: all MNs are contradictions; P-denials are cases of $\mathrm{MN}$ so they too are contradictions; it is this that triggers the move to the $\mathrm{MN}$ interpretation. If he is persuaded by the arguments in the previous section that the presupposition-denial cases are not contradictory, he will have to abandon the view that the 'presupposition'denials are necessarily metalinguistic. However, B-R's intuition that these cases are understood as metalinguistic/echoic is widely shared. A reasonable conclusion, made available by relaxing the contradiction requirement on $\mathrm{MN}$, would be that while they are standardly metalinguistic in use they are not metalinguistic as a matter of logical necessity. Just what this means in practice may not be obvious yet, but the account I spell out in the next 
section will illustrate it. It is this that in fact underlies Horn's alleged dilemma: P-denials ARE understood metalinguistically, but this is pragmatically motivated rather than being forced by a presuppositional semantics.

Let us look now at some of the further evidence that B-R marshals to support his claim that the cancellation of the presupposition is achieved by metalinguistic negation and only by metalinguistic negation. This is of some interest here since if the 'metalinguistic but not necessarily metalinguistic' line is correct this evidence should only support a strong tendency and not a necessity.

Horn gives several 'diagnostics' for the presence of a metalinguistic negation, including: (i) the inability of metalinguistic negation to incorporate prefixally, and (ii) its failure to trigger negative polarity items (NPIs). These are evident in the following examples:

(23) (a) Mary is not happy; she's ecstatic.

(b) !Mary is unhappy; she's ecstatic.

(c) He's isn't tall or handsome; he's tall and handsome.

(d) !He's neither tall nor handsome; he's tall and handsome.

(24) (a) He is sometimes difficult.

(b) !He isn't ever difficult; he is always difficult.

(c) He isn't sometimes difficult; he is always difficult.

The marked examples here can only be understood descriptively and, as a result, they are ruled out because they are contradictory.

B-R points out that these two diagnostics apply to the P-denial cases, thereby giving further support for his view that they are necessarily metalinguistic (on a noncontradictory understanding). Let's look at each of these in turn. B-R (1989b: 236) uses (25a-b) to show that the first diagnostic for $\mathrm{MN}$ is met by the P-denial cases; Horn (1989: 392) also gives those examples, together with $(25 \mathrm{c}-\mathrm{d})$ :

(25) (a) The king of France is not happy - there is no king of France.

(b) !The king of France is unhappy - there is no king of France.

(c) The queen of England is not happy - she's ecstatic.

(d) !The queen of England is unhappy - she's ecstatic.

The claim is that the morphologically incorporated negation in $(25 \mathrm{~b})$ and (25d) does not allow a metalinguistic reading, and so the only interpretation is a descriptive one, which is contradictory and so not acceptable. But there is an important difference between the two examples. First, note that 'unhappy' is a case of term negation, that is, the examples with 'unhappy' are AFFIRMATIVE PREDICATIONS of a negative term, whereas the descriptive uses of 'not happy' are predicate denials, that is denials of the applicability of the term 'happy' to the subject term. See Horn (1989: 40-43) for discussion of this important distinction. Now, in (25b) we could substitute 
for 'unhappy' any predicate term under the sun (or leave it blank) and still get the same result, that is, a contradiction:

(26) (a) !The king of France is sad/healthy/bald/impolite/undressed/etc; there is no king of France.

(b) !The king of France is .........; there isn't any king of France.

This is not so in the case of $(25 \mathrm{~d})$, where only those predicate terms which are semantically antonymous with 'ecstatic' will give rise to a contradiction (some of the others might result in an odd utterance - one whose relevance is difficult to discern - but not a contradiction).

The point is that the utterances which deny the existence of the king of France ((25b) and (26)) do not meet a basic requirement of ANY affirmative predication (whether of a positive or a negative term) which is that its subject should denote something (this is an entailment of these POSITIVE sentences). Thus while it is undoubtedly true that negative prefixes cannot be used metalinguistically (cannot take metarepresentational material in their scope) and that example (25b) is contradictory, these two facts are independent of each other in this example. In short, these facts do not establish that P-denial cases are inevitably metalinguistic.

Let's move to the second diagnostic, the inability of metalinguistic negation to trigger NPIs. (It is discussed and tightened up in Chapman I993 and Carston I998.) Naturally, B-R (I989b: 236) wants to show that the Pdenial cases cannot trigger NPIs, since if they cannot do this the negative presuppositional sentences must be being used metalinguistically. In looking at his examples, given in (27)-(3I), there are two questions to consider. First, is it true that (27)-(3I) are unacceptable, as B-R claims? Second, if we do find them odd, is this because they MUST, due to the unavailability of a noncontradictory semantics, be interpreted metalinguistically.

(27) !The king of France couldn't care less - there is no king of France.

(28) !The king of France doesn't give a damn/hoot - there is no king of France.

(29) !The king of France isn't lifting a finger; there is no king of France.

(30) !The king of France hasn't lost any hair yet; there is no king of France.

(3I) The king of France hasn't lost some hair already; there is no king of France.

(B-R I989b: 236)

The idea, recall, is that these NPIs force a descriptive reading, since they cannot occur in the positive sentences to which a metalinguistic use would be an appropriate rejoinder, for example:

(32) (a) !The king of France could care less.

(b) !The king of France has lost any hair yet. 
So we are really pushed back here to the issue of whether or not these are descriptive contradictions. I've given a lot of evidence that they are not and a comparison of the alleged unacceptability of (27)-(3I) with the following cases merely reinforces this:

(33) (a) !!I don't ever see John; I see him every day.

(b) !!I didn't eat any of the cakes; I ate all of them.

(c) !!She hasn't arrived yet; she's been here all day.

While the nonexistence of a king of France seems an odd reason for denying some property of him, since it renders it pointless (irrelevant), this is not of the same order of unacceptability as the examples in (33), which really are descriptive contradictions.

I shall end this section by briefly considering another problem that $\mathrm{B}-\mathrm{R}$ is led into by his insistence that P-denials are contradictions and must be interpreted metalinguistically (it is discussed at slightly greater length by Horn I990). B-R notes the following possibility:

(34) The king of France isn't bald, because there is no king of France!

and claims that this involves a 'special metalinguistic use of because operating on "the same level", as it were, as that [metalinguistic] use of negation' (B-R I989b: 237). He believes that the same special use of because arises in the second of the following examples:

(35) (a) John has got his hat on because he is going out.

(b) John is going out because he has his hat on.

(35) is an instance of the standard semantic analysis of because: 'P because Q' maps onto ' $\mathrm{Q}$ is a sufficient cause or reason for $\mathrm{P}$ ' and 'Why $\mathrm{P}$ ? For the simple reason that Q'. Mappings of this sort give a bizarre result for $(35 \mathrm{~b})$; for instance, 'Why is John going out? (For the simple reason that) he has his hat on'. In this example, the 'because Q' clause is most naturally understood as providing an explanation of the speaker's reason for SAYING that John is going out; this is what, according to B-R, makes it metalinguistic. The appropriate mapping here would be to 'Why do YOU BELIEVE/SAY that P? For the reason that (I believe that) Q'.

If $\mathrm{B}-\mathrm{R}$ is right about $\mathrm{P}$-denials, applying the first sort of transformation to them should give a bizarre result, while the second sort should be acceptable. Let's see:

(36) (a) Why is the king of France not bald? For the simple reason that there is no king of France.

(b) Why do you believe/say that the king of France is not bald? For the reason that (I know) there is no king of France.

They both seem quite okay. This is just what we should expect if, as I believe I've shown, there is no semantic necessity (no contradiction) forcing these to 
be construed metalinguistically, though they are, as a matter of normal communicative use of natural language, most frequently understood metalinguistically. The because in (34) may be understood as having scope over either a descriptively or metarepresentationally used representation; B$\mathrm{R}$ 's assumption that it can only be used metalinguistically is a byproduct of his erroneous view that the P-denials are descriptive contradictions and that their only coherent interpretation is metalinguistic/echoic.

There are two further issues of interest here, which I merely mention. The first, pointed out by Horn (I990: 499), is that other cases of metalinguistic negation seem less amenable to because conjunction than the P-denials, reinforcing further the difference between them:

(37) (a) !The glass isn't half-empty because it's half-full.

(b) !I didn't shoot two mongooses because I shot two mongeese.

(c) !Grandma isn't feeling lousy, Johnny, because she's badly indisposed.

The second concerns the broad way in which the term 'metalinguistic' is used, both by B-R here, and by Horn (I989: 379-382) in his discussion of socalled metalinguistic uses of other operators, including disjunction, conjunction, the conditional and questions. It is not obvious that the use of because in (35b), giving a reason for a belief or a speech act of the speaker, is 'metalinguistic' in the same sense as it is in the negations we've been looking at, where the crucial ingredient is the echoic or metarepresentational nature of material in the scope of the operator. This whole area needs a lot more examination. ${ }^{6}$

The conclusions of this section are: (i) P-denials are not linguistic contradictions. This is a major problem for B-R's presuppositional semantics. However, contrary to B-R's interdependence view, contradictoriness is not a necessary feature of MN. So this point turns out to have no direct bearing on the issue of whether P-denials are or are not understood metalinguistically; (ii) They ARE most naturally contextualised as rejoinders to a

[6] The issue is especially striking in the context of accounts of conditionals where the term metalinguistic has been used of cases as disparate as the following:

(i) If you're thirsty, there's some beer in the fridge.

(ii) If I may say so, you look better in the red dress.

(iii) If the Cite is the heart of Paris, the Latin Quarter is its soul. (from Horn I989: 380)

(iv) I'll have a tom[a:tou], if that's how you pronounce it.

(v) John managed to solve the problem, if it was at all difficult.

(vi) If you eat tom[eiDouz] you must be American.

(from Dancygier 1992)

(vii) If that glass is half empty you are a pessimist.

(from Noh 1996)

Interesting discussion of these sorts of examples occurs in Sweetser (I990), Dancygier (I992) and Noh (I996), where it seems generally agreed that speech act conditionals and metalinguistic conditionals are distinct sorts of cases. 
prior or anticipated utterance of the positive counterpart of the negation (hence understood metalinguistically), and so tend not to trigger negative polarity items, though this is not an absolute.

What, then, of the strong pretheoretic intuition that there is some tension, if not contradiction, between the first clause and the second, and that they do, frequently at least, require double processing? The analysis I give in the next section, which involves a simple extension to the standard antipresuppositional 'Gricean' analysis, accounts for both of these facts.

\section{A COGnitive pragmatic aCCOUNT OF PRESUPPOSITION- DENIALS}

My recasting and extending of the 'Gricean' account is set within the cognitive pragmatic framework of Sperber \& Wilson's Relevance Theory. While I do not intend to add to the many comprehensive outlines of that framework that are now available, I shall take the next section to foreground some of the commitments of the relevance-theoretic perspective on cognition and communication which have a bearing on my subsequent analysis.

\section{I Relevance-theoretic pragmatics}

Human cognitive activity is relevance-oriented, that is, it is geared towards achieving COGNITIVE EFFECTS, towards processing information which will connect up with our existing representations of the world in certain sorts of extending and deepening ways. It is also geared towards keeping processing costs down, to allocating its limited attentional and inferential resources in an efficient way. The interpretation of utterances is just a particular case of this sort of cognitive activity. However, utterances are a special sort of stimulus in two respects:

A. They are ostensive: they make an overt demand on the hearer's attention, hence his processing resources, and thereby create an expectation that they will achieve a certain level of relevance, known as 'optimal relevance'. So an addressee of an utterance looks for an interpretation of it which has the following two properties:

(I) It achieves at least enough contextual effects to be worth his attention. (II) It puts him no gratuitous processing effort in achieving those effects.

B. They employ a CODE, a language, which directs and constrains the inferential processing of the hearer. This coded element is obviously hugely enabling; it allows speakers to achieve a degree of explicitness, clarity and detail not possible in non-verbal communication (try communicating the proposition expressed by (II) above without using a language). 


\section{SEMANTICS / PRAGMATICS DISTINCTION}

However, the linguistic expressions used on any given occasion of utterance virtually never fully determine what the utterance communicates: there is always a range of possible interpretations which are compatible with the information that is linguistically encoded. I'm referring here not just to the communication of implicatures but also to the proposition explicitly expressed ('what is said') by the utterance. The role of pragmatics in deriving the proposition expressed is far from exhausted by the processes of reference assignment and disambiguation; a great deal of the conceptual material which makes up the truth-conditional content of the utterance is pragmatically inferred. This view, generally known as the linguistic (or semantic) underdeterminacy thesis, is expounded and extensively exemplified in Carston (I988, I998), Atlas (I989), Recanati (1989, I994) and Bach (1994).

Although it is not peculiar to the relevance-theoretic approach to pragmatics, it is more intrinsic to, follows more directly from, the sort of cognitive outlook of this theory than from any other I know of (Atlas and Recanati, for instance, do not develop pragmatic theories of any sort, but assume that something like Gricean maxims will do). Given the relevancedriven propensity, compulsion even, of humans for inferential interpretive activity, triggered both by the inanimate phenomena of the world and by animate 'behaving' phenomena, in particular fellow humans, this capacity is especially likely to be exercised when prompted by ostensive stimuli. Their overt demand for attention can only be justified by a presumption (or promise) of cognitive fruitfulness (optimal relevance). It follows that the coded element of the stimulus should not generally be geared towards achieving as high a degree of explicitness as possible, but should rather take account of the hearer's immediately accessible assumptions and the inferences he can readily draw. When a speaker occasionally fails to take this into account, or gets it wrong, she causes her hearer unnecessary processing effort (for instance, pointless decoding of concepts which are already activated, or highly accessible to him), and runs the risk of not being understood or, at the least, of being found boring and/or patronising, insulting, etc.

A foundational assumption, then, of my own work, within the relevancetheoretic framework, is that utterance interpretation is essentially an inferential matter which involves a bit of helpful semantic decoding to channel the inferencing processes. Pragmatic inferencing may start before the speaker has articulated her first word, may be prompted by an (ostensive) silence on the part of a prospective conversational participant, but will certainly be set in motion by the automatic deliverances of linguistic decoding.

The hearer's inferential capacities not only recover implicated propositions but also resolve linguistic ambiguities, vaguenesses, and referential indeterminacies at the level of the proposition expressed. One of the many indeterminacies to be settled is whether the linguistic representations of the utterance (phonological, syntactic, logical) or its propositional form are 
being used in a basic way (descriptively in the case of a propositional representation) or metarepresentationally (perhaps echoically). If the speaker has judged the hearer's cognitive contextual resources right, the hearer will achieve all this with less mental effort than would be required by a more linguistically explicit utterance (that is, one involving a greater degree of semantic encoding) expressing the same proposition.

It might be worth mentioning two fairly obvious points that follow from this particular cognitive pragmatic view (of a system constantly seeking satisfaction for its efforts). First, if the speaker has left implicit something which could have easily been made explicit and if this leads a hearer to incur extra processing costs, the hearer is entitled to expect extra effects. Gardenpathing cases, including the descriptive-metalinguistic paths above, are clear illustrations of this; the effort involved in taking the one path and then having to backtrack and take another is usually offset by the effects it has (often of amusement). Second, the order in which material is presented has a considerable effect on the interpretation process. A constituent of linguistic encoding is processed in the context of, among other things, assumptions made available by concepts decoded earlier in the text or utterance, so that, in general, the order of clauses (whether conjoined or juxtaposed) affects what gets communicated, while leaving the semantics of the clauses untouched. We saw this already with examples (5) and (6) and its importance for the interpretation of P-denials will be shown shortly. ${ }^{7}$

The semantic underdeterminacy view is not shared by all other pragmatists, and few who acknowledge it hold it in quite as strong a form as the relevance theorists. B-R (I989a, b), for instance, tends toward a rather different weighting of the relative contributions of semantics and pragmatics to utterance interpretation. He favours a heavier element of decoding and tends to look to pragmatics only when the output of the linguistic decoding is defective or insufficient in some way. I shall take up these differences in the last section of the paper.

\subsection{The two pragmatic level account of P-denials}

Recall the two main analyses of (I)-(3) on offer:

A. The Gricean analysis. The semantics of negation is maximally wide in scope (uncommitted) so that the implication that there is a king of France falls within the purview of the negation as a matter of its semantics. This is known as the 'presupposition'-cancelling semantics. The preferred under-

[7] It is worth noting that the on-line processing orientation of this approach to pragmatics makes it open to psycholinguistic experimentation in a way that most of the more logicallybased approaches to pragmatics are not. Sinclair (1995: 527) also makes this point in the context of a comparison of the performance orientation of relevance theory with other cognitive approaches which treat pragmatics as a Chomskyan competence system. Dan Sperber is currently engaged in a programme of experimental testing of relevance-theoretic predictions (see, for instance, Sperber et al. 1995). 
standing on which the existential implication is preserved (or reinstated) is arrived at pragmatically.

B. The presuppositional analysis advocated by B-R. On his account, the preferred presupposition-preserving understanding is a product of the semantics of these sentences and the non-preferred, marked interpretation of (I)-(3) is accounted for pragmatically.

On the surface, these two analyses look like mirror-images of each other:
(38) (a) semantically:
not [the $F$ is $G$ ] via pragmatics: [the $F$ is not-G]
(b) semantically:
[the $F$ is not-G]
via pragmatics:
not [the $F$ is $G$ ]

Using a different notational scheme, B-R himself displays them as mirrorimage analyses in his I99I review of Atlas (I989), but there is a crucial difference, which is that the representation given in ( $38 b)$ as the pragmatically derived presupposition-cancelling case involves metarepresentation. It is given more accurately in (39) which is, of course, importantly distinct from the presupposition-cancelling semantics given in (38a):

(39) not ["the $F$ is $G$ "]

So there are three, rather than two, different schematic representations in play here, and the two approaches do not in fact mirror each other. My claim is that each of the two approaches captures only a part of the full story of the processing and interpretation of the relevant examples. Once we have established an appropriate conception of the role of pragmatics in interpreting P-denials, it will be clear that all three representations are necessary for a full account of the understanding of the relevant examples.

B-R makes several criticisms of the anti-presuppositionalist (Gricean) pragmatic approach, given in (38a). First, he points out its failure to account for the marked, non-preferred status of the 'presupposition'-cancelling interpretation. This is a valid criticism of the externalists, but there is a simple solution to it, which I shall come to very soon. B-R continues his critique in the following vein: 'What, on a non-presuppositionalist semantics, would trigger, and provide the rationale for, a pragmatic reanalysis of the negation as metalinguistic? Nothing whatsoever. The pragmatic reanalysis arises from the need to resolve a problem. On a non-presuppositional semantics, there is no problem...; the negation is semantically analysed as an ordinary, straightforward, truth-functional denial... Such non-presuppositional theories thereby entirely fail to predict that, let alone explain why, the examples in [(I)-(3)] do, as a matter of empirical fact, fall together with [the examples in (4)], evincing all the special features characteristic of metalinguistic uses of negation.' (B-R I989a: I20).

Quite generally, the 'rationale for a pragmatic reanalysis' is provided by the failure of an analysis to meet a pragmatic criterion. Within relevance 
theory this means a failure to deliver a satisfactory range of cognitive effects. Deriving a contradiction, which gives rise to no cognitive effects and so cannot be established as relevant, is just one clear way in which such a failure may arise. This may in fact be what goes on in the case of (I)-(3), at least in those instances which do involve reanalysis. There is nothing, as far as I can see, to rule out an explanation along these lines despite assuming the widescope, 'presupposition'-cancelling, semantics of negation. It will simply involve adding a further step of pragmatic processing to the position given in (38a). Schematically, the picture I propose of the interpretation of the negative sentences in the P-denials, is as follows:

(40) semantically: not [The F is G]

via pragmatic processing (a): [The $F$ is not-G]

via pragmatic processing (b): not ["The $F$ is $G$ "]

Let's take example (I) again, thinking of it now in communicative rather than semantic terms, as an utterance produced and processed over time. As emphasised in the previous subsection, you don't get a pass through the utterance without pragmatic processing. (To try to conceive of this as possible one would have to imagine cutting the language module free from its place within the overall interacting mental system and collecting up its deliverances as they dropped out.) The semantics is the wide-scope negation which has no entailments, (that is, it cancels so-called presuppositions). Since this is too weak/uninformative, in most contexts, to meet the criterion of optimal relevance, the scope of the negation is narrowed so as to achieve sufficient cognitive effects. The negation could, in principle, be taken to target the existential entailment, but processing effort considerations mediate strongly against this, since it would leave the predicate 'is bald' no role to play in the interpretation; the concept will have been activated pointlessly, since it will not enter into the derivation of effects. So the preferred interpretation, preferred because of its relevance-potential, is the narrow scope, 'presupposition'-preserving, interpretation. This is just one of many instances of the process of pragmatic strengthening at the level of the proposition expressed. We would be bound to leave it at that, were it not that some milliseconds later, when we have processed the next (juxtaposed) utterance, we find ourselves with a contradiction: there is a king of France and there isn't a king of France. The overall interpretation of the two clauses is not consistent with the expectation of optimal relevance and a reanalysis is sought. This may be a move to an echoic (metalinguistic) analysis, as in BR's account, though, as shown in (40), on this account it would be at a second level of pragmatic processing. But the reanalysis need not, in principle, involve metarepresentation; it might be a 'return', as it were, to the descriptive wide-scope, 'presupposition'-cancelling interpretation. Which of the two possibilities is the case in any particular instance will depend on the particularities of contexts. 
I do not want to give the impression that these three levels are always inevitably involved or that they are of equal status. The semantic level differs from the two pragmatic levels in that no final interpretation will ever involve it alone. It is the input to the pragmatic inferential processes, an input which comes from the linguistic system not as a whole logical form but bit by bit (perhaps word by word). There are only two levels of actual interpretation and they are identical with B-R's levels, but, and this is the crucial point, these are both levels which are the outcome of pragmatic processes.

In fact, the picture given in (40) is not the only one possible for these utterances. I think there are four possible processing routes for P-denials, for all of which the input is the same semantically uncommitted negation:

I. first pass: pragmatic narrowing (P-preserving) second pass: metalinguistic reanalysis (P-cancelling)

This is the processing track just discussed and it is the most likely for the three examples under discussion; it captures exactly the same intuitions as B$R$ 's analysis, including the intuition of P-preservation under negation, but without assuming a presuppositional semantics.

2. first and only pass: metalinguistic interpretation recognised straight off (P-cancelling)

This is the case of a context in which the metalinguistic interpretation is the most accessible one to the hearer (the least effort-requiring). The reversed metalinguistic cases in (5) and (6) exemplify this, and so do the reversed Pdenials, to be discussed shortly. There are, no doubt, other sorts of contexts too where this occurs, contexts where it is just obvious that the speaker is in the business of echoing someone else's particular utterance or someone's habitual way of expressing himself.

The other two possibilities are less likely, but possible in principle:

3. first pass: pragmatic narrowing (P-preserving)

second pass: pragmatic widening (P-cancelling)

What this amounts to is undoing or repairing a pragmatic strengthening or enrichment. The following seem to be cases where this goes on:

(4I) (a) I have had breakfast. I had it once as a boy many years ago when I had worked all night and was especially hungry.

(b) Edina: Have you eaten?

Patsy: No - not since 1973 .

(from ‘Absolutely Fabulous’ BBC2, 9/2/94)

The on-line temporal enrichment of the first sentence in (a) and of the proposition apparently expressed by Patsy's 'no' in (b) is a narrowing, from 
the semantically encoded temporal span extending back unboundedly from the time of utterance, to a much shorter span contained within the day of utterance. A pragmatic reanalysis takes place as a result of the second clause in each case which is at odds with that temporal enrichment; the original pragmatic narrowing is subsequently pragmatically broadened. Here is a Pdenial case where this seems a likely sequence of pragmatic processes:

(42) A: You always hedge everything. Isn't there anything you feel straightforward simple certainty about?

B: Well, yes, there are a few things I feel sure about. For instance, the king of France isn't bald and he isn't hairy and he isn't tall and he isn't short; there isn't any king of France.

Finally, the least likely option:

4. first and only pass: descriptive interpretation (P-cancelling)

This shouldn't be seen as purely the output of semantics, though it is identical to it; pragmatic inference is involved in deciding that it is the intended interpretation. Here's an example where this seems a likely interpretive path: say we are wig-makers to royalty, well aware of which European countries have monarchs and which don't, and we are making a list of the hirsute monarchs and the bald monarchs, and one of us remarks: 'well, the king of France is neither bald nor hairy'. No doubt, further playing about with examples is needed to establish these last two options as real possibilities.

Let us return now, though, to the first scenario, which is the most likely interpretation and the one which is the direct rival to B-R's account of Pdenials. I think my picture of how this comes about, given in (40), has quite a lot going for it:

(A) It captures the marked feel that most people comment on for the 'presupposition'-cancelling use; this markedness (the extra effects) arises from a pragmatic reanalysis here just as it did on B-R's approach.

(B) It is consistent with the examples in (I)-(3) not being intrinsically (that is, semantically) contradictory, which the evidence in (I8), (I9) and (2I) strongly indicates is the case. In this respect, the analysis has a definite edge on B-R's account which requires, against the facts, that they are semantically contradictory.

(C) The widespread intuition that there is something contradictory here is accounted for by the standard non-presuppositionalist account of the preferred 'presupposition'-preserving understanding. The beauty of this is that it is a PRAGMATIC account, so it is consistent with the non-contradictory semantics of the two clauses while meeting B-R's demand for a 'rationale for the pragmatic reanalysis'.

There is a final clear piece of evidence which makes starkly apparent how very much more satisfactory the two-level pragmatic approach is than the semantic presuppositional account. Recall the cases in section 3.2 in which 
we reversed the negative sentence and the correction clause of metalinguistic negations. This made no difference to the metalinguistic nature of the utterance nor to its status as a semantic contradiction; what it did do was make an important difference to the interpretive process and so to whether or not a hearer was likely to be garden-pathed. A theory of any depth makes predictions about relevant data beyond the limited set it addressed at the outset, so let's see how the two accounts (B-R's and my augmented 'Gricean' account) handle a clause reversal of the P-denial cases:

(43) (a) There is no king of France: so, the king of France is not bald.

(b) The king of France is not bald: there is no king of France.

(44) When did you give up smoking?

(a) I've never smoked in my life (so) I haven't given up smoking.

(b) I haven't given up smoking; I've never smoked in my life.

B-R's account seems to predict that the (a) cases are understood in the same way as the (b) cases, that is, as 'metalinguistic', and that the interpretive stages involved in arriving at that understanding are the same: on a first pass, the negative clauses are taken to be presupposition-preserving, then, understood in conjunction with the other clause a contradiction is reached and, finally, the negative clauses are reanalysed as involving echoic use. Spelling out the interpretive levels for (44a) looks something like this:

(45) I've never smoked in my life. I haven't given up smoking.

level I: (semantics plus bivalence)

Not-P. P and not-Q

(where $\mathrm{P}=\mathrm{I}$ have smoked in my life, and $\mathrm{Q}=\mathrm{I}$ am a non-smoker now)

Result: logical contradiction 'Not-P. P'

level 2: pragmatic reanalysis (giving metalinguistic $\mathrm{P}$-cancelling negation) not ["I have given up smoking"] not ["P and Q"]

But this cannot be right. Placing the 'correction'/explanation clause first effectively prepares the way for the wide-scope (or, perhaps, the echoic) interpretation of the negative presuppositional sentence. The point is essentially the same as that argued above for the examples in (5) and (6) (e.g. 'Maggie is patriotic AND quixotic; she isn't patriotic OR quixotic'): intuitively, there is no garden-pathing here, no on-line contradiction and so no pragmatic reanalysis. The (a) versions of (43) and (44) do not have the marked feel that is typical of the (b) versions, in which the 'correction' or explanation clause follows the negated clause.

The alternative account, on which an all-inclusive semantics for negation is coupled with a psychologically realistic on-line processing view of pragmatics, can capture the intuitive interpretive differences between the (a) and (b) examples, as it is sensitive to the ordering of the clauses. Given the 
context created by the first explanatory clause in each of (43a) and (44a), the subsequent negative utterance may well achieve relevance on its semantically given P-cancelling (non-echoic) understanding and will not need to be narrowed to exclude the 'presupposition' from its scope. Or if, as is quite likely, these are intended as echoic of a previous utterance (say, the question in (44)) and this interpretation is sufficiently accessible to the hearer, they will be so interpreted ON A FIRST PASS, with no initial trying out of a descriptive interpretation and subsequent rejection of it.

The account sketched in (40) involves a small addition to the standard wide-scope 'Gricean' account, a small addition which incorporates what is right about B-R's account, that is, what captures the markedness intuition, without making the various false predictions that drastically undermine his account. It should be clear that Horn's (alleged) dilemma has dissolved, that an account of P-denials which takes negation to be semantically P-cancelling (Horn's predicate denial, for instance), but which recognises that in communicative use these are most often metalinguistic, is neither incoherent nor redundant.

However, the new improved analysis might be viewed by some with Occamite suspicion, since it involves three interpretive tiers, the semantic and the two pragmatically arrived at understandings, whereas both of the original competitors had only two. There are two points to make in response to any such worry: first, my claim is that it takes three levels to do justice to the interpretive facts; economy principles can be brought into play only when the analyses being assessed all cover the same set of data, which, as I've shown, is not the case here. This counting of levels should really be dropped and replaced by counting interpretations, in which case there are two here as in both the previous accounts; it's just that neither of them coincides with what is semantically encoded. Second, the richer account I'm proposing, in fact, calls for no increase in semantic apparatus (in this regard it comes cheaper than B-R's presuppositional semantics) or in pragmatic principles. What it does postulate is more interpretive work being done with those pragmatic principles than either of the original accounts allowed for. In the last section I would like briefly to address this matter, but in a wider context in which the assumptions underlying B-R's talk of the 'appeal' or 'resort' to pragmatics can be compared with the relevance-theoretic view given in section 6.I.

\section{The SEMANTICS/PRAGMATICS DistinCtion}

What lies behind B-R's work is a conception of pragmatics as a fairly thin icing on a substantial semantic cake. Recall his assertion, mentioned in the previous section, that the wide-scope 'presupposition'-cancelling negationists do not have the means to explain what triggers the pragmatic reanalysis in cases where this takes place. This in fact depends on a more 
basic assumption expounded elsewhere in his book: ' $\ldots$ if we wish to claim that the understanding evidenced in [(I)-(3)] is a matter for pragmatics, then it is NOT an understanding of negation characterised directly by the semantics. We are thereby committed to deriving this understanding of negation [the metalinguistic] from another understanding, WHERE THIS OTHER UNDERSTANDING IS DIRECTLY CHARACTERISED BY THE SEMANTICS, INDEED IS THE SEMANTIC READING ITSELF.' (B-R I989b: 228, my emphasis).

He takes this to be an argument which supports his contention that natural language negation is semantically presupposition-preserving (or at least not presupposition-cancelling). It can only have this force if the claim is that the metalinguistic understanding, which is patently pragmatic, is derived DIRECTLY from the understanding which is provided by the semantics (or by semantics plus the bivalence requirement on his 1993 account). The quoted passage does not say this explicitly, but it appears to be what is meant, since it would otherwise not support any of the semantic accounts he was assessing there, whether P-preserving or P-cancelling. Since the understanding that the metalinguistic analysis is derived from is the one which involves nonbaldness being predicated of an existing king of France it must be that that is given by the semantics (plus, again, the default application of bivalence).

If the stipulation given in this quotation were correct quite generally, it would immediately rule out my analysis in (40). But is there any reason to think that every case of a pragmatically arrived at understanding must be directly derivable from an understanding given by the semantics? In particular, why should we believe this of a case which is agreed to involve deliberate garden-pathing and reanalysis? Consider mildly jokey christmas cracker type examples such as that in (46). Like the examples B-R is interested in, its effect depends on hearers being garden-pathed, realising this and reanalysing:

(46) Q: Why do birds fly south in winter?

$\mathrm{R}$ : Because it's too far to walk.

The reader/hearer of the interrogative initially takes the 'why' to concern the 'southward' direction of the birds' movement. The second utterance does not, however, provide an answer to that question, but to another question which involves a different understanding of the first utterance, an understanding on which the 'why' concerns the birds' mode of travel. Would we want to say that the initial, rejected understanding is semantically encoded, that is, that the 'why' is tied to 'south' as a matter of the semantics of the sentence? Surely not, but this is what B-R's stipulation commits him to: the second ('correct') understanding, which is undoubtedly arrived at pragmatically, must be derived from an understanding 'directly characterised by the semantics'. The initial interpretation here is patently not a matter of semantics alone but the outcome of pragmatic processing involving 
stereotypical knowledge about birds, knowledge which makes their flying an unlikely focus of the 'why' question. This strikes me as entirely analogous to the 'presuppositional' negation cases: semantically, both the negation operator and the 'why'/'because' clause are unspecified as to the constituent they may focus on, so on any interpretation the choice of focus is a matter for pragmatic inference.

There is a more general point to be made here regarding cases where a speaker deliberately garden-paths a hearer for effect. On the relevancetheoretic view, pragmatic inferencing starts as soon as a hearer recognises a stimulus as ostensive (that is, as communicatively intended); it would be quite remarkable, then, in cases of garden-paths which involve revision of an entire initial interpretation, if that first interpretation were wholly a matter of semantics.

We do not have to look at 'clever' cases, where the speaker is deliberately manipulating addressees' assessments of relevance, to see that B-R's constraint on the role of pragmatics in utterance interpretation is far too tight. Consider simple mistakes on the part of hearers in performing the pragmatic processes of reference assignment and disambiguation. A revision of one of these processes will, obviously, take place as a result of the first, PRAGMATICALLY arrived at, hypothesis not meeting one's pragmatic criterion. It is quite generally the case, then, that when a pragmatic reanalysis is undertaken, it is on the basis of a prior pragmatically derived understanding. Of course, ultimately, back at the beginning as it were, there is a semantic decoding that kicks the inferencing mechanism into action, but the point I am trying to make here is that there may be several layers of pragmatic processing, and that the final understanding may have been derived from a previous pragmatically derived understanding. B-R cannot find support for his 'presupposition'-preserving semantics for negation simply by observing that the metalinguistic understanding is pragmatically derived; nothing follows from this about the semantic or pragmatic nature of the understanding it is derived from.

A closely related but distinct assumption is what I have called, in section 4.2, B-R's semantic-pragmatic disjunction thesis: that the result of a pragmatic reanalysis cannot account for a property of the interpretation that the semantic analysis of the sentence/utterance could account for. This underlay his view of Horn as caught in a double bind, by virtue of advocating a semantically P-cancelling negation AND a pragmatically arrived at metalinguistic negation interpretation of the P-denials. The essence of the supposed problem is that both are P-cancelling. Indeed they are, but this is not a problem; in fact, both are necessary in order to account fully for the interpretation of the P-denials, as I believe I have shown in the previous section.

Here is another stipulation from B-R: 'An operator whose understanding is specifically provided for by the semantics of the language should not result 


\section{SEMANTICS / PRAGMATICS DISTINCTION}

in any feeling of markedness or specialness when actually applied.' (B-R I989b: 40) He is, of course, adverting here to the markedness of the widescope, P-cancelling, semantics for negation favoured by Horn, Wilson, Kempson, etc, and finding favour for a semantics for negation which induces a default P-preservation, since this is the unmarked understanding. I have shown in (40) how the markedness intuition is comfortably accommodated within the anti-presuppositionalist approach; in general, it is not the wide scope DESCRIPTIVE understanding that is in operation on the marked interpretation, so that the quoted precept does not apply to this account. However, it's worth considering as a general point of principle, independently of the issues around negation, since it is indicative of B-R's view of semantics and pragmatics.

When we look at the interpretation of utterances in the broader context of human interpretive activity in general, it is far from obvious that what is 'specifically provided for by the semantics of the language should not result in any feeling of markedness', that it should feel natural, should be the preferred understanding, while marked or unusual interpretations should be the result of pragmatic processes. I doubt that there are any absolute statements to be made regarding the correlation of naturalness or unnaturalness of interpretations with bare semantics, semantics plus cognitive bivalence requirements, or pragmatics. However, viewing linguistic decoding as, on the whole, providing mere propositional schemas, which function as clues and directives to the interpretive process, rather than fully fledged articulations of thoughts and assumptions, does quite forcefully undermine the view that the deliverances of semantics should be more natural, or less marked, than the thought-shaped representations that are rapidly, and virtually automatically, inferred by the relevance-driven cognitive system. While the sort of markedness that cases of garden-pathing and reanalysis give rise to must be accounted for pragmatically, there is no reason at all to assume that the natural but 'wrong' interpretation, the garden-path, is either the product of linguistic semantics alone, or is particularly closely tied to it.

By way of illustration, let's take what has now become the classic case of pragmatic enrichment (from Sperber \& Wilson I986: I89):

(47) (a) I have had breakfast.

(b) I have been to Tibet.

Although both examples employ the same linguistic construction for the expression of tense, these two utterances would usually be understood as communicating rather different temporal spans: while (47b) might reasonably be taken to refer to the speaker's lifetime up to the time of utterance, (47a) is most likely to be taken to refer to a much shorter interval, involving just the day of utterance up to the point of utterance. As far as I am aware, 
no-one wants to posit a semantic ambiguity in the past perfect, such that each of its (infinite) senses covers a different time-span. There may be differences of opinion as regards where the pragmatically derived meaning surfaces whether as an implicature or as a pragmatic enrichment of the proposition expressed - but that issue need not be settled here. The point is that these 'natural' understandings are indisputably pragmatic and the linguistically given semantics of the tense operator would indeed be felt to be special or marked if it were not pragmatically narrowed.

This point can be further pushed by consideration of just about any of the cases of what Griceans call 'generalised' conversational implicature. These involve a pragmatic process which takes place quite generally across contexts, unless it is specifically blocked by particular contextual factors; it is often referred to as a default inference. So, to take just a couple of examples:

(48) (a) You can have a cake or a biscuit.

(b) Billy ate some of the cakes.

The neo-Gricean semantics for 'or', with which I believe B-R is in agreement, is the inclusive understanding, and for 'some' it is the lowerbounded 'at least' understanding. However, most linguistically untutored, native speakers take 'or' to be exclusive; this is the natural, preferred interpretation, while the inclusive understanding which is 'specifically provided for by the semantics of the language' is the more marked understanding. On a neo-Gricean account, the 'natural' understandings of (48a) and (48b) are pragmatically derived; in each case, there is a conversational implicature which, taken together with the proposition expressed, gives the preferred understanding: the exclusive ('either but not both') understanding of 'or' and the 'some but not all' understanding of 'some'. The cautious conclusion, then, is that there is no reason to suppose that the meanings provided by the semantics of the language should surface, untouched by pragmatic inference, as the constituents of the preferred interpretation. We might well want to go further and say that, given the underdeterminacy thesis and the immediate and prolific nature of pragmatic inferencing, natural interpretations are bound to carry a pragmatic contribution. Nothing follows, yet again, as regards whether natural language negation should be regarded as P-cancelling (marked) or Ppreserving (unmarked) or neither P-cancelling nor P-preserving. That must be established on other grounds, as, I believe it has been, in this paper and elsewhere.

I have given this brief survey of some of the assumptions B-R makes about the nature of semantics and of pragmatics, and about the relation between them, in order to show some of the underpinnings of his arguments against a 'presupposition'-cancelling semantics of negation. Both his view that a 


\section{SEMANTICS / PRAGMATICS DISTINCTION}

pragmatic reanalysis must be derived directly from a semantically given understanding and his view that unmarked, or natural, interpretations should be direct reflections of the semantics of operators (albeit completed to meet bivalency) appear to be false. Both issue from considerable underestimation of the role of pragmatic inference in the understanding of utterances.

\section{REFERENCES}

Atlas, J. (I977). Negation, ambiguity and presupposition. Linguistics and Philosophy I. 32 I-336. Atlas, J. (1989). Philosophy without ambiguity. Oxford: Clarendon Press.

Bach, K. (1994). Conversational impliciture. Mind and Language 9. I24-I62.

Boer, S. \& Lycan, W. (1976). The myth of semantic presupposition. Indiana University Linguistics Club.

Burton-Roberts, N. (I989a). On Horn's dilemma: presupposition and negation. Journal of Linguistics 25. 95-I25.

Burton-Roberts, N. (I989b). The limits to debate. Cambridge: Cambridge University Press.

Burton-Roberts, N. (I990). Trivalence, gapped bivalence, and ambiguity of negation: a reply to Seuren. Journal of Linguistics 26. 455-470.

Burton-Roberts, N. (199I). Review of Atlas, J. Philosophy without ambiguity. Mind and Language 6. I6 I-I76.

Burton-Roberts, N. (1993). On preservation under negation. Newcastle and Durham Working Papers in Linguistics I. I8-4I. [Reprinted (1997) in Lingua I0I. 65-88.]

Carston, R. (1988). Implicature, explicature and truth-theoretic semantics. In Kempson, R. (ed.) Mental representations: the interface between language and reality. Cambridge: Cambridge University Press. I55-I8I. [Reprinted in Davis, S. (ed.) (I99I). Pragmatics: a reader. Oxford: Oxford University Press. 33-5I. Reprinted (with postscript) in Kasher, A. (ed.) (I998). Pragmatics: critical concepts. London \& NewYork: Routledge. vol. 4. 436-479.]

Carston, R. (I994). Metalinguistic negation and echoic use. UCL Working Papers in Linguistics 6. 32 I-339. [Revised version (I996) in Journal of Pragmatics 25. 309-330.]

Carston, R. (1998). Pragmatics and the explicit/implicit distinction. Ph.D. dissertation, University of London. [To be published by Blackwell.]

Carston, R. \& Noh, E.-J. (I995). Metalinguistic negation is truth-functional negation, with evidence from Korean. UCL Working Papers in Linguistics 7. I-26. [Reprinted (I996) in Language Sciences I8. 485-504.]

Chapman, S. (I993). Metalinguistic negation, sentences and utterances. Newcastle and Durham Working Papers in Linguistics I. 74-94.

Cormack, A. (I980). Negation, ambiguity and logical form. Ms., University College London.

Dancygier, B. (1992). Two metatextual operators: negation and conditionality in English and Polish. Berkeley Linguistic Society I8. 6I-75.

Foolen, A. (I99I). Metalinguistic negation and pragmatic ambiguity: some comments on a proposal by Laurence Horn. Pragmatics I. 21 7-237.

Gazdar, G. (1979). Pragmatics: implicature, presupposition, and logical form. New York: Academic Press.

Grice, H. P. (I98I). Presupposition and conversational implicature. In Cole, P. (ed.), Radical pragmatics. New York: Academic Press. I83-198. [Reprinted in Grice, H. P. (1989). Studies in the way of words. Cambridge, MA: Harvard University Press. 269-282.]

Horn, L. (I985). Metalinguistic negation and pragmatic ambiguity. Language 6I. I2 I-I74.

Horn, L. (1989). A natural history of negation. Chicago: University of Chicago Press.

Horn, L. (I990). Showdown at truth-value gap: Burton-Roberts on presupposition. Review of Burton-Roberts 1989. Journal of Linguistics 26. 483-503.

Horn, L. (1992). The said and the unsaid. Ohio State University Working Papers in Linguistics (SALT II Proceedings) 40. I63-192.

Kempson, R. (1975). Presupposition and the delimitation of semantics. Cambridge: Cambridge University Press.

Kempson, R. (1986). Ambiguity and the semantics-pragmatics distinction. In Travis, C. (ed.), Meaning and interpretation. Oxford: Blackwell. 77-I04. 


\section{ROBYN CARSTON}

Lappin, S. \& Reinhart, T. (I988). Presuppositional effects of strong determiners: a processing account. Linguistics 26. I02 I-I037.

Lasersohn, P. (1993). Existence presuppositions and background knowledge. Journal of Semantics I0. I I3-I 22.

Noh, E.-J. (I996). A relevance-theoretic account of metarepresentative uses in conditionals. UCL Working Papers in Linguistics 8. I25-I63.

Recanati, F. (I989). The pragmatics of what is said. Mind and Language 4. 295-329.

Recanati, F. (1994). Contextualism and anti-contextualism in the philosophy of language. In Tsohatzidis, S. (ed.), Foundations of speech act theory. London \& New York: Routledge. I $56-$ I 66

Seuren, P. (I988). Presupposition and negation. Journal of Semantics 6. I75-226.

Seuren, P. (1990). Burton-Roberts on presupposition and negation. Journal of Linguistics 26. 425-453.

Sinclair, M. (1995). Fitting pragmatics into the mind: some issues in mentalist pragmatics. Journal of Pragmatics 23. 509-539.

Sperber, D., Cara, F. \& Girotto, V. (I995). Relevance theory explains the selection task. Cognition 57. $3 \mathrm{I}-95$.

Sperber, D. \& Wilson, D. (198I). Irony and the use-mention distinction. In Cole, P. (ed.), Radical pragmatics. New York: Academic Press. 295-3I8.

Sperber, D. \& Wilson, D. (I986). Relevance: communication and cognition. Oxford: Blackwell; Cambridge, MA: Harvard University Press.

Sweetser, E. (1990). From etymology to pragmatics. Cambridge: Cambridge University Press.

Turner, K. (I992). Defending semantic presupposition. Journal of Pragmatics I8. 345-37I.

Wilson, D. (I975). Presupposition and non-truth-conditional semantics. New York: Academic Press.

Wilson, D. \& Sperber, D. (I988). Representation and relevance. In Kempson, R. (ed.), Mental representations: the interface between language and reality. Cambridge: Cambridge University Press. I $33-$ I 53.

Wilson, D. \& Sperber, D. (I992). On verbal irony. Lingua 87. 53-76.

Wilson, D. \& Sperber, D. (I993). Pragmatics and time. UCL Working Papers in Linguistics 5 277-298. [Revised version in Carston, R., \& Uchida, S. (eds.) (1998). Relevance theory: applications and implications. Amsterdam: John Benjamins, I-22.]

Author's address: Department of Phonetics and Linguistics, University College London

Gower Street

London WCIE 6BT

U.K.

E-mail:robyn@ling.ucl.ac.uk 